\title{
Residents' Democratic engagement in public housing and urban areas - structures, formalities and technologies
}

\author{
Olav W. Bertelsen \\ Aarhus University \\ Denmark \\ olavb@cs.au.dk \\ Carolin Schröder \\ TU-Berlin \\ Germany \\ c.schroeder@ztg.tu-berlin.de
}

\author{
Henrik Korsgaard \\ Aarhus University \\ Denmark \\ korsgaard@cs.au.dk
}

Yngve Sundblad
Royal Institute of Technology
Sweden
y@kth.se

\author{
Ingrid Kuhn \\ Liquid Democracy \\ Germany \\ ingrid.kuhn@liqd.de \\ Konrad Tollmar \\ Royal Institute of Technology \\ Sweden \\ konrad@kth.se
}

\begin{abstract}
The workshop gathers people from various sectors inside and outside academia to discuss the current state of, and the prospects for IT in the support of residents' democratic engagement in, and around, public housing.
\end{abstract}

ACM Classification Keywords

K.4.m. Computers and Society: Miscellaneous Author Keywords

Public housing; decision-making; residents' democracy

\section{SHORT DESCRIPTION OF THE WORKSHOP}

The workshop brings together perspectives on residents' engagement and influence in the development of their housing estates and housing areas, and will explore experiences and potentials for the use of ICT in this context. The workshop builds on earlier workshops on similar issues [e.g. 4].

Public housing around the world is organized very differently, and in particular the models for residents influence have radically different forms. In Denmark residents are at the same time landlords and tenants, but do not own anything and are subject to strong legal and municipal regulation. In Sweden residents are organized in a strong union of tenants and have acquired wide rights to be consulted in important cases. It is unclear where residents have the strongest influence. In many other countries, residents in public housing projects have no influence at all, unless they organize themselves. Residents' engagement depends on a lot of different circumstances, cultures, and conditions. If residents live in an estate because they did not have any other options their

Copyright $\odot 2015$ is held by the author(s). Publication rights licensed to Aarhus University and ACM

5th Decennial Aarhus Conference on Critical Alternatives August 17-21, 2015, Aarhus Denmark

DOI: http://dx.doi.org/10.7146/aahcc.v1i1.21391 engagement may be weaker than it would be if they made a free choice. We do not expect that any engagement is fundamentally different through social media than in everyday face-to-face encounters, but we find it interesting to explore how - and to what extent - ICT can break barriers, constitute new forms of engagement or contribute to local democratic structures for different groups of people or mobilise for political influence locally and nationally.

New media create new opportunities by allowing residents to organize and express themselves and bridges across time and space as well as competency gaps. While recognizing this and the potential in ICT, the workshop will take a critical stance to technology in relation to residents' engagement in their housing estates or neighbourhoods and political influence on decisions. ICT may, on the one hand, indeed keep people away from social engagement in their housing estate and may limit their will to influence decisions just as much as the opposite - on the other hand, ICT may increase participation by offering user-friendly tool and thus support the inclusion of the citizens, independent living and networking for different groups of people. Just as in any other area of society, the so-called digital divide influences who can and will participate and how (see e.g. [1]), both when organizations are increasingly using web-portals and online services as an entry point and when part of the day to day encounters and communication moves into social networks. Here it is relevant to ask what form of social or political participation social networks offer: Are they indeed the great liberators, do they play a more pacifying role, or do they change nothing at all? Does connectivity by itself ensure participation (see e.g. [9])? What about accessibility and usability? New media offer new possibilities but how can you create the best conditions for ICT to really make a difference? A similar question is whether the services and mediated participation offered by a given housing organizations website question the role technology plays in democratic representation [2]. Finally, 
it is also clear that software and ICT is playing a role in shaping neighbourhoods and urban areas [8].

This discussion requires an initial exploration of different structures for residents' involvement, together with current issues that residents' engagement faces around the world. Here, we seek to focus on the interplay between the existing structures (legal, economic, organizational, political etc.), (degree of) formalities and level/form of participation [1], and existing technologies, in influencing democratic engagement and participation.

The focus of the workshop is on democratic engagement in public housing and residential areas, but we also aim to use this as a basis for broader scientific discourse on democratic engagement in relation to, and supported through technology.

\section{KEY TOPICS}

In the workshop a number of issues identified in the original call as well as in the submissions will be explored.

\section{Framing public housing}

Public housing constitutes a specific thematic and political area for implementation of ICT. As public housing is organized differently around the world, one of the potential tasks for the workshop is to gain a shared and basic understanding of the characteristics of the public housing sector, how it is organized and regulated within the different countries, and which socio-cultural as well as economic aspects shape the conception of public housing. This will help us understand the landscapes, particularities and differences in order to identify scopes for using ICT in that context. One focus of the workshop is to relate ICT to different age and gender groups and their specific ideas of public housing, residency, communities, neighbourhood or place-bound organizations. [3]

\section{Challenges and potentials in ICT}

The workshop participants will, based on the contributions and the characterizations, discuss both the challenges and potential of new media and information technology within the frame of public housing and democratic engagement. Just as the public housing organizations are different, so are the local uptake of and particular collection of technologies already in use by residents and public housing organizations. While some technologies are well-known, e.g. social media and global commercial tools, others are tailor-made and locally adopted. This creates a mix of challenges and potentials that will be discussed at the workshop. How do we work with the existing platforms and practices? What role should/could new (novel) technologies play? How do we avoid repeating the mistakes and focus on the under-developed areas and challenges left behind by commercial industry and the past [2]?

\section{Examples of ICT based support for residents engagement}

From our point of view, and examples from the position papers, it seems to be necessary to differentiate between the following activities and participation with ICT support. a) integrating ICT in the public housing context (i.e. different degrees of participation): e.g. for information, interaction, data collection, consultation, collaboration, planning of common facilities and decision-making.

b) different groups of participants and users.

c) social and political participation: ICT may be of good use for senior citizens when sustaining independent (smart) living, but ICT may also be useful for young people in a large housing estate for social networking and ICT may be helpful for special interest groups (families, singles, wheelchair users) to organize collective action - in all three cases ICT would be structured and used completely different. ICT, e.g. through social media, may also be a tool for political action to improve conditions for public housing. And there are many more to be found.

\section{Role of the research community in public housing}

The topics of the workshop indicate a renewed research interest in public housing and democratic engagement, which in turn may lead to research projects and collaboration. At the workshop we will discuss potential roles for the research community in public housing in the future. How do we approach the research area and with what agenda? What do we need to do inter- and transdisciplinary research in that context? Do we engage in partnerships or smaller projects? How do we ensure some degree of sustainability, both in terms of the potential technologies researchers introduce (new and old) and the challenges arising from our engagement?

These questions are related to accountability and commitment [12], (socio-technical) sustainability [11] and moving from (hit and run) projects to more long-term engagement [6] and different models of collaboration (e.g. living labs [5]). Does the topic and area of research merit a specific approach, e.g. action research, participatory design or ethnomethodology?

\section{Revisiting previous discourse}

The idea that democratic engagement can be empowered through the application of technology is not new. Historically, the printing press has been used to distribute bulletins to residents, channelling debate and information about activities. Today, most public housing organisations in Denmark and the tenants' organisations in Sweden have a printed magazine distributed to their tenants. Over the years local TV, TeleText and various portal solutions have been seen as a road to popular engagement. Hampton [9] argues, based on a large scale community networking project, that ICT has potentials to facilitate community participation, but also points simple asynchronous solutions to be more promising than advanced multimedia.

In the age of mobile app's it seems tempting to try to solve issues such as residents' opportunity apathy and the receding popular engagement in local decision-making by smart phone based solutions. The workshop will take a critical perspective on the history in order not to fall into 
naïve techno-optimism. What has changed in terms of technology and maturity? Did the previous efforts release the potential? What challenges are left behind? Are there lessons from other technology and democracy studies with ICT support, in workplace, leisure and domestic settings [7, $10,13]$ that can be carried over to the housing sector?

\section{STATUS AND OUTLOOK}

The workshop includes 11 submissions from a broad range of participants. The position papers raged from descriptions of the state of residents' democratic engagement in specific countries, over reports on specific design experiments and studies of democratic engagement, to introductions of systems to support residents' engagement. Participants had backgrounds in non-profit organisations, housing organisations as well as in academia.

The workshop attendance demonstrates a growing interest and research in the area of computer support for residents' democratic engagement. This could hopefully lead to the establishment of formal research collaboration around the topic, e.g. through European research funding.

Follow-up from the workshop including more detailed accounts on the contributions to the workshop will be published in the Aarhus Series on Human Centred Computing. ${ }^{1}$

\section{ABOUT THE ORGANIZERS}

Olav W. Bertelsen is an associate professor with the Department of Computer Science at Aarhus University, his research interests include human-computer interaction and user involvement. He has been engaged in the Danish public housing sector for more than two decades, as chairman for a housing organization, board member and activist.

Henrik Korsgaard, is a PhD-candidate with the Department of Computer Science and the Centre for Participatory IT at Aarhus University. His research interests include urban computing and place-specific computing. He has previously worked with media architecture, urban interaction design and Public Sector Information (open data).

Ingrid Kuhn works as a project manager at the non-profit association Liquid Democracy, based in Berlin. The main project, which Ingrid Kuhn manages relates to the development of a central participation platform for the city of Berlin, called mein.berlin.de, which bundles different types of participation processes such as the one related to the urban land use planning.

Carolin Schröder is Head of the Participation Research Unit at the Centre for Technology and Society, Technische Universität Berlin. Her research interests are sustainable urban development, urban governance and democracy, cooperatives as well as inter- and transdisciplinary research.

\footnotetext{
${ }^{1}$ http://ojs.statsbiblioteket.dk/index.php/ashcc/
}

Carolin has been engaged in bottom-up neighborhood development and co-operative housing in Berlin for many years. One of her current projects is: FlashPoll Developing a municipal decision-making App, www.Flashpoll.eu.

Yngve Sundblad Yngve Sundblad is professor emeritus in Computer Science / Human-Computer Interaction at KTH in Stockholm. His research interests include humancomputer Interaction and user participation. He has been active in Hyresgästföreningen (Swedish Union of Tenants) for more than 40 years with experience in local organization, tenants' influence and negotiations with landlords, especially in community-owned public housing.

Konrad Tollmar is a professor of computer science at the Royal Institute of Technology specialized in human computer interaction and interaction design.

\section{REFERENCES}

1. Arnstein, Sherry R. "A ladder of citizen participation." Journal of the American Institute of planners 35.4 (1969): 216-224.

2. Aurigi, A. 2006. New technologies, same dilemmas: policy and design issues for the augmented city. Journal of urban technology, 13(3), 5-28.

3. Bertelsen, O.W. (2014). Overcoming Residents Opportunity Apathy in Danish Social Housing Democracy. International Reports on SocioInformatics, 11(1), 45-54.

4. Bertelsen, O.W., Bødker, S., de Cindio, F., Pipek, V. (2014). Proceedings of the COOP 2014 Workshop on Collaborative Technologies in Democratic Processes. International Reports on Socio-Informatics 11(1). International Institute for Socio-Informatics, ISSN 1861-4280.

5. Björgvinsson, E., Ehn, P., \& Hillgren, P. A. (2010, November). Participatory design and democratizing innovation. In Proceedings of the 11th Biennial Participatory Design Conference (pp. 41-50). ACM.

6. Botero, A., \& Hyysalo, S. (2013). Ageing together: Steps towards evolutionary co-design in everyday practices. CoDesign, 9(1), 37-54.

7. Bødker, S., Sundblad, Y. (2008). Usability and Interaction Design - new challenges for the Scandinavian tradition. Behaviour and Information Technology. ), vol.27, no.4, pp 293-300.

8. Dutton, W. H., Kraemer, K. L., and Blumler, J. G. 1987: Continuity and Change in conceptions of the Wired City, in Dutton, W. H., Kraemer, K. L., and Blumler, J. G. (Ed.) (1987). Wired cities: Shaping the future of communications. pp. 3 - 26, Macmillan Publishing Co., Inc..

9. Hampton, Keith N. "Grieving for a Lost Network: Collective Action in a Wired Suburb" The Information Society, Vol. 19 pp. 417-428, 2003 
10. Lindquist, S., Westerlund, B., Mackay W. and Y. Sundblad. (2007). Co-designing communication technology with and for families - methods, experience,results and impact for the future. In The Disappearing Computer Heidelberg: Springer-Verlag.

11. Merkel, C. B., Xiao, L., Farooq, U., Ganoe, C. H., Lee, R., Carroll, J. M., \& Rosson, M. B. (2004, July). Participatory design in community computing contexts: Tales from the field. In Proceedings of the eighth conference on Participatory design: Artful integration: interweaving media, materials and practices-Volume 1 (pp. 1-10). ACM.

12. Suchman, L. (2002). Located accountabilities in technology production. Scandinavian journal of information systems, 14(2), 7.

13. Westerlund, B. and Sundblad, Y. (2015). Design as Democratic Process - and Implications for Innovation. Ch.2 in Action Research for Democracy: New Ideas and Perspectives from Scandinavia, Routledge 